\title{
ICE ACCRETION UNDER NATURAL AND LABORATORY CONDITIONS
}

by

\author{
K. Itagaki, G. E. Lemieux and H. W. Bosworth
}

US Army Cold Regions Research and Engineering Laboratory, Hanover, New Hampshire 03755

\section{ABSTRACT}

To compare results of icing studies conducted in wind tunnels with natural icing conditions, a series of rotor icing studies were made on top of Mt. Washington, New Hampshire. The results indicated that considerable differences exist between the two under conditions of similar liquid water content and temperature. The wet-to-dry growth transition temperature, for instance, with comparable temperature and liquid water content, may be more than $10^{\circ} \mathrm{C}$ higher under natural conditions than in wind tunnel studies. The possible cause of such discrepancies was found to be the vapor saturation existing in most laboratory experiments. The transition temperature of ice accretion measured in natural fog on board an aircraft agreed better with the results of the Mt. Washington study.

\section{INTRODUCTION}

Ice accumulation is a severe problem in the operation of fixed and rotating wing aircraft in cold moist environments. Extensive engineering investigations on ice accumulation have addressed loss of flying efficiency of aircraft but little consideration has been given to the nature of ice accumulation itself. The effect of rotation or possible differences in conditions between natural and laboratory testing have been of little concern. To gain more scientific perception of ice accretion problems, particularly in regard to rotating struts, tests were undertaken at the top of Mt. Washington in Jefferson, New Hampshire, under natural conditions, and the results were compared with those from previous tests made under laboratory conditions.

\section{EQUIPMENT}

Two pairs of different cross-sectional blades (a pair of $68.5-\mathrm{cm}$-radius airfoil with a chord of $16 \mathrm{~cm}$ and a pair of $67.5-\mathrm{cm}$-radius and $3.81-\mathrm{cm}$-diameter cylinder) were mounted symmetrically (Figure 1). This rotor was

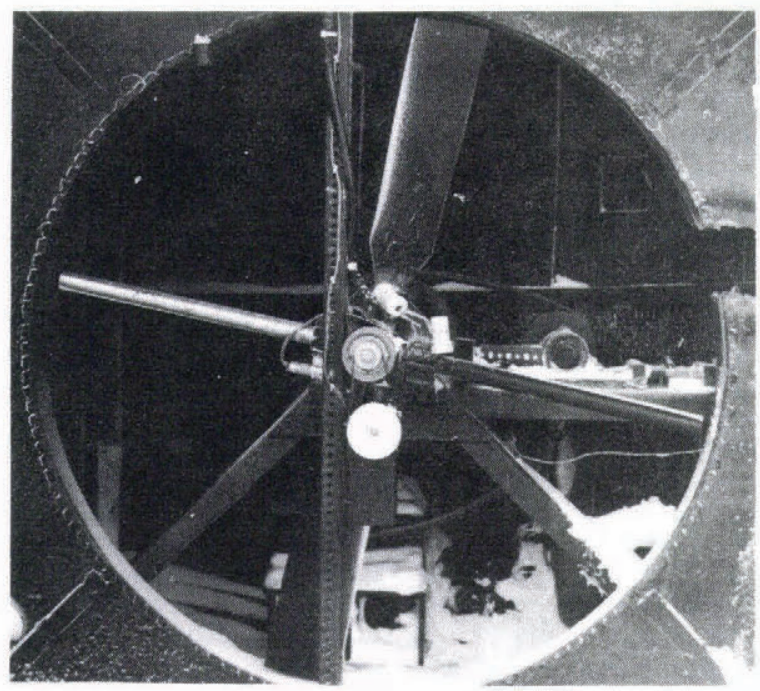

Fig.1. Wide airfoil blades and cylindrical blades were mounted and tested to compare the difference caused by the different cross sections under identical conditions. driven up to 2000 RPM by a gasoline engine. A shelter was provided to protect the blades from severe weather conditions. A set of doors closed off openings between tests, but were opened to provide free air circulation during operation. Three pairs of thermistors were placed at the tip $(\mathrm{R}=67 \mathrm{~cm})$ midpoint $(\mathrm{R}=47 \mathrm{~cm})$ and hub $(R=26.5 \mathrm{~cm})$ of the leading edge and at $1 / 3$ the chord, on one of the airfoil cross-sectional blades. Temperatures measured by the thermistors, the strain of the blade measured at the hub, vibration and other weather data were recorded with a Datel DL-2 data logger. The resolution of the logger itself was about $0.01{ }^{\circ} \mathrm{C}$, but heavy noise caused by a nearby TV station located at the summit reduced overall accuracy about $0.5^{\circ} \mathrm{C}$.

Liquid water content (LWC) was measured by personnel of the Mt. Washington Weather Station, also located at the summit. They used a multi-cylinder, following the Langmuir Blodgett method. The results are shown in column 6 of Table 1 .

Two new tests of equipment were developed and used during the experiments. A "laser profiler" was designed to photograph the profile of accreted ice perpendicular to a laser-illuminated narrow strip. A "roto-scope" was used to observe the rotating rotor blades by following the blades optically. Detailed descriptions of these devices will be published elsewhere.

\section{RESULTS AND DISCUSSION}

The main objective of this study was to understand the icing phenomenon under natural conditions and compare it with the laboratory experiments. Effort was made to obtain quantitative results as far as possible but problems caused by severe natural conditions and limitations in man-power prevented us from obtaining all data at a consistent level. However, considerable qualitative differences were observed between laboratory and natural conditions. A summary of all icing runs is presented in Table 1 .

\section{Wet to dry growth regime transition}

All natural accretions observed in the present studies at temperatures below $-8^{\circ} \mathrm{C}$ were of the dry type regardless of location on the blade or LWC, indicating that the blades were in the dry growth regime at windspeeds up to $150 \mathrm{~m} / \mathrm{s}$. In contrast, in our laboratory rotor experiments (Ackley and others 1979), complete dry growth conditions started only below $-24^{\circ} \mathrm{C}$ and at a LWC around $1 \mathrm{~g} / \mathrm{m}^{3}$. Moist growth conditions in which liquid water exists but does not migrate were between -14 and $-23^{\circ} \mathrm{C}$. Experiments at higher than $-14^{\circ} \mathrm{C}$ were entirely in the wet growth regime.

Lozowski and others (1979) observed dry growth conditions only at a temperature of $-15^{\circ} \mathrm{C}$, LWC 0.4 $\mathrm{g} / \mathrm{m}^{3}$ and a wind speed of $30 \mathrm{~m} / \mathrm{s}$ when no ice particles were added. With the addition of ice crystals of 0.1 to $0.3 \mathrm{~g} / \mathrm{m}^{3}$ they claimed that the dry growth range expanded to $-5^{\circ} \mathrm{C}$ for a LWC of $0.4 \mathrm{~g} / \mathrm{m}^{3}$ and wind speed $92 \mathrm{~m} / \mathrm{s}$. However, the appearance of accumulated ice noted in their report indicated that the ice particles were collected on the wet surface.

Stallabrass and Hearty (1979) made a series of icing tests using the same icing wind tunnel as Lozowski and others (1979) but a different ice particle generator called a "snow nozzle", which generated large numbers of 
TABLE 1. ICE RUN SUMMARY. NOTES: A: TEMPERATURES MANUALLY MEASURED; B: THICKNESS OF ACCRETED ICE ESTIMATED FROM BLADE PHOTOS; C: THICKNESS ESTIMATED FROM LASER PROFILER; D: TWO SPEED RUNS MADE CONSECUTIVELY.

\begin{tabular}{|c|c|c|c|c|c|c|c|c|c|c|c|c|c|c|}
\hline \multirow{3}{*}{$\begin{array}{c}\text { No. } \\
1\end{array}$} & \multirow{2}{*}{\multicolumn{2}{|c|}{ Date/Time }} & \multirow{3}{*}{$\begin{array}{l}\text { Temp. } \\
\left({ }^{\circ} \mathrm{C}\right) \\
-5.0\end{array}$} & \multirow[t]{2}{*}{$\begin{array}{l}\text { Wind } \\
(\mathrm{m} / \mathrm{s}) \\
\end{array}$} & \multirow[t]{2}{*}{ RPM } & \multirow[t]{2}{*}{$\begin{array}{l}\text { LWC/DIa. } \\
\left(\mathrm{g} / \mathrm{m}^{3} / \mathrm{m}\right)\end{array}$} & \multirow{2}{*}{\multicolumn{3}{|c|}{$\begin{array}{l}\text { Th I dk/Rate/Loc. } \\
\frac{(\mathrm{mm})(\mathrm{\mu m} / \mathrm{s})(\mathrm{cm})}{A \mid r \mathrm{foll}}\end{array}$}} & \multicolumn{3}{|c|}{$\begin{array}{l}\text { Th I ck/Rate/ Loc. } \\
(\mathrm{mm})(\mu \mathrm{m} / \mathrm{s})(\mathrm{cm}) \\
\end{array}$} & \multirow[t]{2}{*}{ Regime } & \multirow[t]{2}{*}{ Notes } \\
\hline & & & & & & & & & & & I Inder & & & \\
\hline & 24 & Apr $1977 / 2000$ & & $12 \mathrm{E}$ & 1200 & $0.52 / 28 \mathrm{~J}$ & 3.0 & 5.6 & 10 & & & & Wet/Dry & A \\
\hline 2 & 26 & Apr $1977 / 1731$ & -2.2 & $8.5 \mathrm{~W}$ & 2000 & $0.72 / 160$ & 9.0 & 12.5 & 15 & & & & Wet & \\
\hline 3 & 12 & Mar 1978/1059 & -8.0 & $16 \mathrm{~W}$ & 1500 & $0.45 / 90$ & 6.0 & 4.7 & 3 & 3.0 & 2.36 & 46 & Wet/Dry & B \\
\hline 4 & 231 & Mar $1978 / 1540$ & -8.0 & $17 \mathrm{~W}$ & 1800 & $0.54 / 11 \mathrm{C}$ & 15.0 & 7.9 & 16 & & & & Wet/Dry & \\
\hline 5 & 28 & Mar $1978 / 1440$ & -10.5 & $21 \mathrm{~W}$ & 1800 & $0.54 / 118$ & 3.0 & 4.7 & TIP & & & & & \\
\hline 6 & 31 & Mar 1978/1354 & -12.0 & $20 \mathrm{~W}$ & 1600 & $0.51 / 100$ & 6.0 & 4.8 & 9 & 2.0 & 1.6 & 5 & & \\
\hline 7 & 7 & Apr $1978 / 1526$ & -6.8 & $3 \mathrm{NW}$ & 2000 & & 7.6 & 13.1 & 12 & 5.1 & 8.8 & 12 & Wet & C \\
\hline 8 & 14 & Apr 1978/1139 & -8.9 & $21 \mathrm{~W}$ & 1000 & $0.675 / 186$ & 8.0 & 8.7 & 15 & & & & Dry & \\
\hline 9 & 15 & Apr $1978 / 1340$ & -12.0 & $19 \mathrm{~W}$ & 400 & $0.36 / 11 \mathrm{~B}$ & 4.5 & 3.8 & TIP & 2.5 & 2.1 & TIP & Dry & \\
\hline 10 & 5 & Apr $1979 / 1405$ & -7.5 & $20 \mathrm{~W}$ & 1600 & $0.5 / 11 \mathrm{~B}$ & 4.2 & 4.3 & 4 & 4.1 & 4.3 & 10 & Dry & \\
\hline 11 & 19 & Apr $1979 / 1530$ & -8.0 & $14 \mathrm{~N}$ & 1800 & & 1.5 & 1.6 & 10 & 1.0 & 1.1 & 5 & Dry & C \\
\hline 12 & 14 & Jan $1980 / 0558$ & -5.0 & $21 \mathrm{w}$ & 2000 & $1.07 / 17 \mathrm{~J}$ & 7.0 & 6.8 & 20 & 4.4 & 4.3 & 15 & Wet/Dry & D \\
\hline 13 & 14 & Jan 1980/1535 & -3.0 & $18 \mathrm{~S}$ & 1500 & & 2.6 & 6.2 & 5 & 2.7 & 6.4 & 20 & Wet/Dry & \\
\hline 14 & 15 & Apr 1980/1930 & -2.0 & $15 \mathrm{~W}$ & 2000 & & 3.6 & 4.7 & 5 & 2.0 & 2.6 & 5 & Wet & \\
\hline 15 & 16 & Apr 1980/0643 & -6.0 & $6 \mathrm{~W}$ & 2000 & & 1.3 & 1.1 & 10 & 1.0 & 0.9 & 5 & Wet/Dry & \\
\hline 16 & 16 & Apr $1980 / 1535$ & -10.0 & $21 \mathrm{NW}$ & 2000 & & 3.7 & 4.4 & 5 & 2.5 & 2.9 & 5 & Dry & A \\
\hline
\end{tabular}

minute ice particles having a median diameter of $15 \mu \mathrm{m}$ was used. The ice particles sprayed by the "snow nozzle" caused drastic differences in morphological aspects. Especially at lower wind speeds, the cross section became wedge-shaped. At higher wind speeds the cross section resembled a rather truncated wedge. Stallabrass and Hearty observed a dry growth regime at $-15^{\circ} \mathrm{C}$, LWC 0.4 $\mathrm{g} / \mathrm{m}^{3}$ and a wind speed $61 \mathrm{~m} / \mathrm{s}$ without ice particles. Judging from the photograph in their Figure 5, this condition may have been a moist growth regime. With the addition of ice particles of $1.0 \mathrm{~g} / \mathrm{m}^{3}$, the dry growth rose to $-5^{\circ} \mathrm{C}$, for a LWC of $0.4 \mathrm{~g} / \mathrm{m}^{3}$ and a wind speed of $30 \mathrm{~m} / \mathrm{s}$. Tests made at wind speeds higher than 30 $\mathrm{m} / \mathrm{s}$ were all in the wet growth regime.

As discussed by Stallabrass and Hearty, concentrations of ice particles produced by their "snow nozzle" could not be oberved in the natural case. All wet growth regime results by Lozowski and others were under the comparable conditions of $-8^{\circ} \mathrm{C}$, LWC of 0.12 $\mathrm{g} / \mathrm{m}^{3}$ without ice crystal or $0.28 \mathrm{~g} / \mathrm{m}^{3}$ and ice crystal content (ICC) of $0.8 \mathrm{~g} / \mathrm{m}^{3}$ at a wind speed $110 \mathrm{~m} / \mathrm{s}$. We observed pure dry growth regime under comparable conditions of $-7.5^{\circ} \mathrm{C}$, LWC of $0.5 \mathrm{~g} / \mathrm{m}^{3}$ and maximum wind speed of $115 \mathrm{~m} / \mathrm{s}$. The amount of ICC was not measured in our studies and was expected to be widely variable, but even if an amount of ice particles comparable to that of Stallabrass and Hearty existed in the present studies, the wet to dry growth regime transition was at a much higher temperature under natural conditions than in the laboratory since wind speeds were much higher.

Several sources of discrepancies can be pointed out.

a) Temperature measurements in the present studies were made in natural fog but the sensor was protected so that little or no ice accretion occurred. Ambient temperature was used for the laboratory rotor experiments (Ackley and others 1979), and the real temperature in the fog was presumably much higher than the ambient temperature due to spraying warm water. Apparently Lozowski and others (1979) deduced the test section temperature from their plenum chamber temperature controller setting. One example given by them was a plenum temperature of $+2.5^{\circ} \mathrm{C}$, relative humidity (RH) of $90 \%$ and static pressure of 1013.25 $\mathrm{mb}$, which would give $-5^{\circ} \mathrm{C}$ at an air speed of $120 \mathrm{~m} / \mathrm{s}$ at the test section. So great a temperature drop would increase RH to $195 \%$ over ice even without the introduction of any water drops. Possible supersaturation could lower the apparent transition temperature by either supplying more liquid water or raising temperatures by latent heat of condensation or both. The test section static temperatures for Stallabrass and Hearty's tests were derived from direct measurements of dry tests, but problems similar to those that Lozowski and others encountered may still exist. Also rapid freezing of droplets from their "snow nozzle" could release heat, affecting the results.

The spray nozzle for Ackley and others was placed only $50 \mathrm{~cm}$ from the rotor so that droplets had little time to cool down and considerable vapor was generated from the warm droplets. There are many published icing studies but most give insufficient detail to estimate RH. For instance no detailed geometry was given by Laforte and others (1983). Considering the size and configuration of their cold room and wind tunnel, conditions similar to those of Ackley and others would apply. Such a humid environment may also exist in the Ottawa spray rig (Stallabrass 1958) since the rig uses steam to atomize water and releases extensive water vapor along with the droplets.

b) Liquid water supply under natural conditions, especially for all test systems used in the present studies, is close to the snow surface, and thus can be lower than the value obtained by multi-cyclinder measurements at the observatory tower about $20 \mathrm{~m}$ higher. Nearby snow surface and blown-up snow particles are a good vapor sink. Comparison between near-equilibrium natural conditions and highly transient laboratory test conditions of all four tests cited here seems difficult, but the water supply through the vapor phase in an icing wind tunnel can be much higher than under the natural conditions of the present studies.

Compared with the very large latent heat of freezing, the heat content of droplets only few degrees higher than ambient temperature would cause little change in wet to dry growth transition temperature. However, supersaturation of vapor caused by evaporating warm cloud droplets (as in the laboratory environment) could supply a large amount of water and also cause some temperature rise. Calculations made by Lowell (1953) indicated that the vapor supply from individual droplets is small for small obstacles, but continuous flow of a large number of droplets could provide a significant water supply through the evaporation and condensation process. Frequently we observed crystallographic (high faceted) surfaces especially near the edge of the accretion, indicating a vapor growth condition existing at that location. 


\section{Droplet Capture Efficiency Index (DCEI)}

In order to compare data given by various authors certain common measures have to be devised. Probably a quantity (amount of captured water/amount of supply) could serve reasonably well as such a measure. Let us call this quantity the droplets capture efficiency index (DCEI). Of course DCEI is a function of various parameters such as incoming droplet size distribution and air velocity, geometry and material of the collecting structure, as well as supply rate and temperature. Since we measure the rate of thickness increase $R_{c}$ DCEI $\left(E_{i}\right)$ can be defined as

$$
\mathrm{E}_{\mathrm{i}}=\mathrm{R}_{\mathrm{c}}^{*} \mathrm{\rho} / \mathrm{V} * \mathrm{~W}
$$

where $\mathrm{V}$ is air velocity, $\mathrm{W}$ is LWC, and $\rho$ is the density of accreted ice. The density of accreted ice is fairly close to $0.9 \mathrm{~g} / \mathrm{cm}^{2}$ under the high-speed impact conditions found in the most parts of the present blade. Velocity V can be calculated from rotor RPM and radial location of the accretion. The same definition can be applied to similar types of measurements which measure thickness growth rate (Stallabrass and Hearty Hearty, and Lozowski and others). Some measurements, such as those of Bain and Gayet (1982), were expressed by the rate of cross-sectional area increase. We have to be content with an average growth rate by assuming that the collection area stays constant. In Figure 2 DCEI calculated from present field observation data are plotted together with those of Lozowski and others, Stallabrass and Hearty,

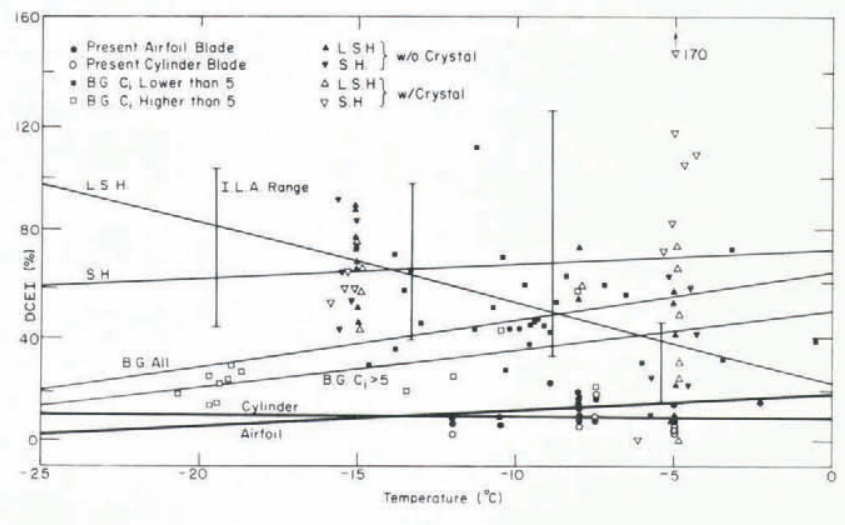

Fig.2. Droplet capture efficiency index (DCEI) calculated from various reports as a function of temperature. results indicated that icing wind tunnel study DCEIs are higher than those under natural icing studies.

and Bain and Bayet. Also some of our laboratory rotor experiment results, partly published by Ackley and others, part in oreoaration by Itagaki and others are shown by vertical lines indicating the range of DCEI. Since DCEI differs depending on the radial location on the rotor, only the range is shown. Examples of the radial distribution of DCEI obtained from our laboratory rotor experiments are shown in Figure 3 . The laboratory rotor results cover the range of DCEI calculation from data given by Lozowski and others. Extensive ice crystal injection seems to have shifted higher temperature points of Stallabrass and Hearty considerably. Their lower temperature points and higher temperature without ice crystal injection seem unaffected, and agree with Itagaki and others and Lozowski and others. Although the points are scattered widely, several features can be pointed out.

1) Present measurements give the lowest DCEI of all other measurements.

2) DCEI calculated for natural icing measurements of aircraft by Bain and Gayet, especially with ice particle counts $C_{i}$ higher than $5 / L$, are much lower than those of the laboratory rotor icing by Itagaki and others, and the icing wind tunnel studies by Lozowski and others, and Stallabrass and Hearty.

Two possible causes contributed to the lower DCEI

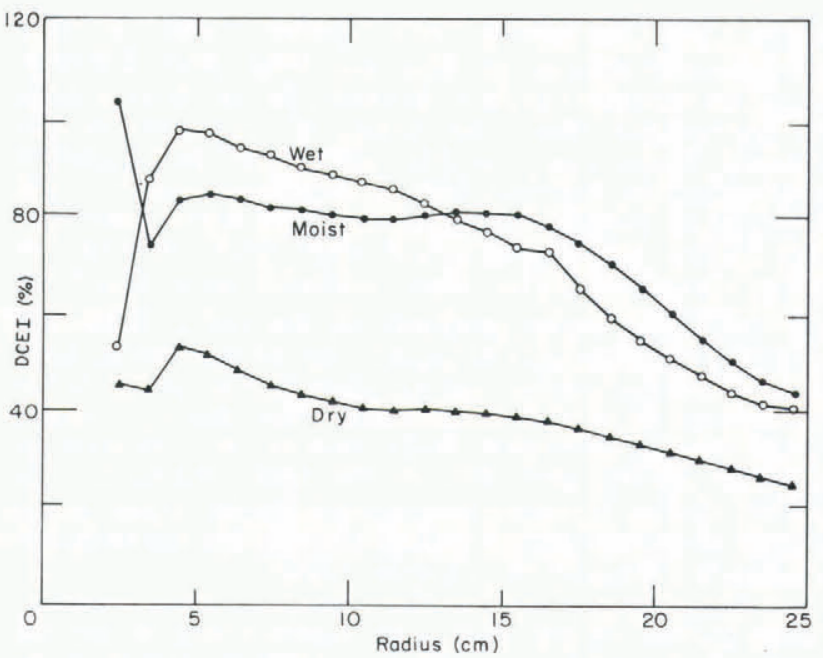

Fig.3. Radial distribution of DCEI of wet, moist, and dry conditions obtained from laboratory studies showing the effects of centrifugal acceleration and radial air flow caused by rotation of the rotor (Itagaki and others, to be published).

for the present studies. The abundant supply of ice crystal is one. As shown in Figure 2, the regression line for Bain and Gayet of high crystal count of $C_{i}$ (they arbitrarily set it at $5 / \mathrm{L}$ ) especially at higher temperatures, is much lower than the all-inclusive line, indicating that high ice count is a major factor contributing to lower the present DCEI. However, no further lowering trend of DCEI for $C_{i}$ higher than $5 / \mathrm{L}$ can be observed in the results by Bain and Gayet, indicating that a further reduction mechanism is involved in our results. The other factor of lower DCEI is the centrifugal force field and air flow in the radial direction along the high speed rotor blades. As shown in Figure 3, DCEI measured in laboratory conditions (Itagaki and others) gradually drops by an increase in radial location of the blades beyond the disturbed area near the hub. According to Langmuir and Blodgett (1946) collection efficiency $E_{M}$ is a function of $K$ and $\Phi$, and both are proportionally increased with velocity $U$. Although $\Phi$ tended to reduce $E_{M}$, higher values of $K$ cause an increase in $E_{M}$ as a whole within the range of the present study. Overall, an increase of DCEI with an increase in $U$ is expected from Langmuir and Blodgett's theory. This result is an opposite trend to that found in rotor experiments since rotor blades encounter higher wind speed with an increase in radial location of the blades.

Two possible causes could contribute to this discrepency. Centrifugal acceleration would be especially effective in moving free water in wet growth condition. Since radial components of air flow are combined with the normal component of oncoming to blade surface, droplets carried by the air flow do not impinge the rotor blade perpendicularly, reducing the collection efficiency. A gradual drop in DCEI of dry growth case may be mainly caused by such a mechanism.

Humps in the curve appearing around the $15-\mathrm{cm}$ radius for the moist growth case may be caused by the outward motion of migrating water. More active migration of water in the wet case may help to shed water, causing DCEI to be actually lower than in the moist case. Because most of the natural icing rate was measured near the tip, any of the reducing mechanisms would make DCEI much lower than in the nonrotating case. Present results seem to agree reasonably well after such adjustment, with Bain and Gayet having a $C_{i}$ higher than $5 / \mathrm{L}$.

\section{Morphological aspects}

The laser profile camera was used on eight icing runs and thin section studies were made in six runs. At higher temperatures and wind speeds, Lozowski and 
others, and Stallabrass and Hearty observed that accretion extended more than $90^{\circ}$ from wind direction along the cylinder surface. However, in the natural icing in the present study, the extent of accretion on the cylinder blades stayed within $\pm 60^{\circ}$ from the stagnation lines along the cylinder, with a pronounced hump along the edge of accretion for even the most severe case (run 13). A few cone-shaped grains were found beyond the edges. Contrary to the rather moderate icing found on the cylindrical blades, accretion on the airfoil blade has a flat-nosed rough profile outside the $40-\mathrm{cm}$ radius. Such a cross section would greatly degrade the performance of a rotor or propeller. It appears that the two humps found on the cylindrical blade were merged, eliminating the flat smooth part due to the small radius on the airfoil blades. If such merging of humps takes place, simple modeling using a certain scaling law may not be applicable (Armand and Charpin 1976).

Runs number 7,12 and 15 were in slightly wet or moist growth regimes and small humps appeared but we never encountered the type of accretion described by Stallabrass and Lozowski (1978) as a "thin cornice-like sheet" nor did we observe the "mushroom-double-horn" observed by Laschka and Jesse (1978). Probably ice of weaker mechanical strength could not survive under the dynamic conditions found in the rotor experiments. As discussed in previous papers (Itagaki 1983a, b) such accreted ice would shed before reaching a thick protrusion.

\section{CONCLUDING REMARKS}

Ice accretion on high speed rotors of both airfoil and cylindrical cross section blades was studied under the identical natural icing conditions on top of Mt. Washington, New Hampshire. The results were compared with those from the various other studies made under natural conditions and in icing wind tunnels.

The features found in icing wind tunnel studies made at certain temperatures, LWCs, and wind speeds generally correspond to much warmer and higher LWCs in the present studies. Our results fit more closely to observations made under natural conditions, although many factors such as closeness to the vapor absorbing snow surface, high thermal conductivity of the solid metal blades, centrifugal force and radial direction flow field may induce a shift towards drier growth conditions in our results. The major cause of this discrepency may be the higher relative humidity that apparently existed in most icing wind tunnel studies.

With the limited number of observations made in the widely variable natural conditions, we cannot rule out the possibility of encountering the conditions observed in icing wind tunnels, such as very high supersaturation. However, we believe that we have identified the important parameter, relative humidity, that was previously disregarded in connection with the ice growing regime and transition temperature.

\section{REFERENCES}

Ackley S F, Lemieux K, Itagaki K, O'Keefe J 1979 Laboratory experiments on icing of rotating blades snow removal and ice control research. Special Report 185, Transportation Research Board. National Academy of Science: $85-96$

Armand C, Charpin F 1975-76 Icing testing in the large Mondane tunnel on a reduced-scale model of a helicopter rotor. L'Aeronautique et l'Astronautique (in French) no 55, 1975-76, PM-28. CRREL Draft Translation 523 May 1976.

Bain M, Gayet J F 1982 Aircraftmeasurements of icing in supercooled and water droplets/ice crystal clouds. Journal of Applied Meteorology 21: 631-641

Itagaki K 1983a Mechanical ice release processes I. Self-shedding from high speed rotors. CCREL Report 83-26

Itagaki K 1983b Self-shedding of accreted ice from high-speed rotors. American Society of Mechanical Engineers. Publication 83-WA/HT
Laforte J L, Phan C I, Felin B, Martin R 1983 Adhesion of ice on aluminium conductor and crystal size on the surface layer. Proceedings of First International Workshop on Atmospheric Icing of Structures. CRREL Special Report 83-17: 83-91

Langmuir I, Bodgett K B 1946 A mathematical investigation of water drop trajectories. AAF Technical Report 5418

Lascha B, Jessee R E 1978 Ice accretion and its effects on aerodynamics of unprotected aircraft components. NATO, AGARD Advisory Report November 1978, no 127, AGARD Fluid Dynamics Panel Roundtable Discussion on aircraft Icing, Ottawa, Spetember 20, 1977, Proceedings: $5 / 1-5 / 20$

Lozowski E P, Stallabrass J R, Hearty P F 1979 The icing of an unheated non-rotating cylinder in liquid water droplet-ice crystal clouds. National Research Council, Canada, Report LTR-LT-96

Lowell H H 1953 Maximum evaporation rates of water droplets approaching obstacles in the atmosphere under icing conditions. NACA Technical Note 3024

Stallabrasss J R 1958 Canadian research in the field of helicopter icing. Journal of Helicopter Association of Great Britain 12: 169-206

Stallabrass J R, Hearty P B 1979 Further icing experiments on an unheated non-rotating cylinder. National Research Council, Canada, Report LTR-LT-105

Stallabrass J R, Lozowski E P 1978 Ice shapes on cylinder and rotor blades. NATO Army Armament Group Panel $X$. Helicopter Icing Symposium 6-7, November 1978, London 